\title{
CHEMICAL COMPOSITION OF THE ESSENTIAL OILS OF ANETHUM GRAVEOLENS L.
}

\author{
Mohsen Kazemi*and Vahid Abdossi \\ Department of Horticultural Science, Faculty of Agricultural Science and Natural Resources, \\ Science and Research Branch, Islamic Azad University, Tehran, Iran
}

Key words: Anethum graveolens, Chemical composition, Essential oils

\begin{abstract}
The volatile constituents of the leaves of Anethum graveolens L., growing wild in Iran, were investigated by GC/MS, $\alpha$-Phellandrene $(29.12 \%)$, limonene $(26.34 \%)$, dill ether $(15.23 \%)$, $\alpha$-pinene $(2 \%)$, $n$-tetracosane $(1.54 \%)$, sabinene $(1.34 \%)$, neophytadiene $(1.43 \%)$, n-docosane $(1.04), n$-tricosane $(1 \%)$, $n$-nonadecane $(1 \%), n$-eicosane $(0.78 \%), n$-heneicosane $(0.67 \%), \beta$-myrcene $(0.23 \%)$ and $\alpha$-tujene $(0.21 \%)$ were found to be the major constituents of the oil.
\end{abstract}

Anethum graveolens L. (Fam.: Umbellifrae) commonly known as Dill, is an annual medicinal plant with tiny yellow flowers. A. graveolens seeds are widely used in food and pharmaceutical industries. In traditional medicine, Dill seeds are used against gastrointestinal problems and rheumatism (Grosso et al. 2008). On the other hand, seed augments the appetite and strengthen the stomach (Zargari 1996). The major part $(90 \%)$ of the dill fruit's oil consists of d-carvone, d-limonene, and $\alpha$-phellandrene. The remaining include: dillanoside, kaempferol and 3-glucuronide compound, vicenin, myristicin and other flavonoids, phenolic acids, proteins and fats (Zargari 1990, Valady et al. 2010). The present work was undertaken to determine the chemical composition of essential oils from A. graveolens wild growing in several locations of Ilam, Iran.

A. graveolens leaves were ground and the resulting powder was subjected to hydrodistillation for $3 \mathrm{hrs}$ in an all glass Clevenger-type apparatus according to the method recommended by the European Pharmacopoeia (1975). The obtained essential oils was dried over anhydrous sodium sulphate and after filtration, stored at $+4^{\circ} \mathrm{C}$ until analysed.

The GC/MS analyses were executed on a Hewlett-Packard 5973N gas chromatograph equipped with a column HP-5MS ( $30 \mathrm{~m}$ length $\times 0.25 \mathrm{~mm}$ i.d., film thickness $0.251 \mathrm{~m}$ ) coupled with a Hewlett-Packard $5973 \mathrm{~N}$ mass spectrometer. The column temperature was programmed at $50^{\circ} \mathrm{C}$ as an initial temperature, holding for $6 \mathrm{~min}$, with $3^{\circ} \mathrm{C}$ increase per minute up to the temperature of $240^{\circ} \mathrm{C}$, followed by a temperature enhancement of $15^{\circ} \mathrm{C}$ per min up to $300^{\circ} \mathrm{C}$, holding at the mentioned temperature for $3 \mathrm{~min}$. Injector port temperature was $290^{\circ} \mathrm{C}$ and helium was used as carrier gas at a flow rate $1.5 \mathrm{ml} / \mathrm{min}$. Ionization voltage of mass spectrometer in the EI-mode was equal to $70 \mathrm{eV}$ and ionization source temperature was $250^{\circ} \mathrm{C}$. Linear retention indices for all components were determined by coinjection of the samples with a solution containing homologous series of $\mathrm{C}_{8}-\mathrm{C}_{22} n$-alkanes and comparing them and their mass spectra was compared with those of authentic samples or with available library data of the GC/MS system (WILEY 2001 data software) and Adams libraries spectra (2001).

*Author for correspondence: <kazemimohsen85@gmail.com>. 
The essential oil was extracted from the leaves of A.graveolens L. by hydrodistillation with a yield of $1.05 \%$. GC/MS analyses of the oil led to the identification of 14 different components, representing $81.93 \%$ of the total oil. The identified compounds are listed in Table 1 according to their retention index relative to $n$-alkanes. Monoterpenic hydrocarbons were found predominant in the leaf oil. The major components in the oil detected were $\alpha$-phellandrene (29.12\%), limonene

Table 1. Chemical composition of essential oil from leaves of A. graveolens.

\begin{tabular}{lcc}
\hline Compounds & Percentage & Kovats retention indices \\
\hline$\alpha$-Tujene & 0.21 & 920 \\
$\alpha$-Pinene & 2.00 & 932 \\
Sabinene & 1.34 & 970 \\
$\beta$-Myrcene & 0.23 & 990 \\
$\alpha$-Phellandrene & 29.12 & 1002 \\
Limonene & 26.34 & 1017 \\
Dill ether & 15.23 & 1180 \\
Neophytadiene & 1.43 & 1799 \\
$n$-Nonadecane & 1.00 & 1900 \\
$n$-Eicosane & 0.78 & 2001 \\
$n$-Heneicosane & 0.67 & 2054 \\
$n$-Docosane & 1.04 & 2118 \\
$n$-Tricosane & 1.00 & 2227 \\
$n$-Tetracosane & 1.54 & 2387 \\
Total & 81.93 & \\
\hline
\end{tabular}

(26.34\%), dill ether (15.23\%), $\alpha$-pinene (2\%), $n$-tetracosane (1.54\%), sabinene $(1.34 \%)$, neophytadiene $(1.43 \%), n$-docosane $(1.04), n$-tricosane $(1 \%), n$-nonadecane $(1 \%), n$-eicosane $(0.78 \%)$, n-heneicosane $(0.67 \%), \beta$-myrcene $(0.23 \%)$ and $\alpha$-tujene $(0.21 \%) . \quad \alpha$-Phellandrene and dill ether are the compounds, which form the important odor of Dill herb (Blank and Grosch 1991). Ashraf et al. (1997) analyzed the Dill seed essential oil by GLC and found the oil to be rich in carvone (52.25\%), Dill apiole (28.28\%) and limonene (9.34\%). Singh et al. (2005) reported carvone $(55.2 \%)$, camphor $(11.44 \%)$, limonene $(16.6 \%)$ and Dill apiole $(14.4 \%)$ to be the key components present in the essential oil extracted from the seeds of $A$. graveolens. However, there were significant differences among the rates of those reported components.

\section{References}

Adams RP 2001. Identification of essential oils components by gas chromatography/quadra pole mass spectroscopy. Carol Stream, IL, Allured. 61-367.

Asraf M, Aziz J and Bhatty MK 1997. Studies on the essential oils of the Pakistani species of the family Umbelliferae. Part VI. Anethum graveolens (Dill, Sowa) seed oil. Pakistan J. Sci. Ind. Res. 20(1): 52-54.

Blank I and Grosch W 1991. Evaluation of potent odorants in dill seed anddill herb (Anethum graveolens L.) by aroma extract dilution analysis. J. Food Sci. 56: 63-67.

European Pharmacopoeia 1975. Vol. 3, Maisonneuve S. A., Sainte-Ruffine.

Grosso C, Ferraro V, Figueiredo AC, Barroso JG, Coelho JA and Palavra AM 2008. Supercritical carbon dioxide extraction of volatile oil from Italian coriander seeds. Food Chem. 111: 197-203. 
Singh G, Maurya S, Lampasona MPD and Catlan C 2005. Chemical Constituents, Antimicrobial Investigations, and Antioxidative Potentials of Anethum graveolens L. Essential Oil and Acetone Extract: Part 52. J. Food Sci. 70(4): 208-215.

Valady A, Nasri S, Abbasi N and Amin G 2010. Antiinflammatory and analgesic effects of hydroalcoholic extract from the seed of Anethum graveolens L. J. Med. Plants. 9: 130-124.

Zargari A 1996. Medicinal Plants. 6th ed., Vol. II, Tehran University Press, Tehran. 531-528.

(Manuscript received on 22 July, 2014; revised on 21 August, 2014) 